\title{
Fabrication of Diatomite/Silicalite-1 Composites and Their Property for VOCs Adsorption
}

\author{
Yutong Liu and Tao Tian * \\ Key Laboratory of Groundwater Resources and Environment, Ministry of Education, College of New Energy \\ and Environment, Jilin University, Changchun 130012, China; liuyt841011@163.com \\ * Correspondence: tiantao@jlu.edu.cn
}

Received: 18 January 2019; Accepted: 11 February 2019; Published: 13 February 2019

\begin{abstract}
Adsorption technology is an effective method to remove volatile organic compounds (VOCs). In this work, we prepared hierarchical porous materials using modified diatomite (Dt) as a support and nano-sized silicalite-1 (S-1) seeds as inorganic fillers, which were applied to adsorb volatile organic compounds (VOCs). The characterization of the composites indicated that S-1 was successfully coated onto the surface of modified $\mathrm{Dt}$, and the best surface area of the composites was $398.8 \mathrm{~m}^{2} / \mathrm{g}$, nearly 40 times as large as Dt. The adsorption capacities of Dt/S-1 composites for three probe VOCs (ethyl acetate, acetone, and toluene) were rather superior to Dt, and the composites had preferential adsorption selectivity for ethyl acetate. Effects of seeded zeolite contents and hydrothermal conditions for the adsorption capacity of composites were discussed in this paper. The composite seeded with $5 \mathrm{wt} \% \mathrm{~S}-1$ zeolite, which was subsequently synthesized by hydrothermal reaction at $100{ }^{\circ} \mathrm{C}$ for four days, showed the maximum adsorption capacity $(1.31 \mathrm{mmol} / \mathrm{g}$ for ethyl acetate). The pseudo second-order model provided a perfect fit to adsorption kinetics, while the Langmuir model agreed the best with the adsorption isotherms. In addition, the composites had selective adsorption to ethyl acetate among these three probes VOCs. The regeneration experiments were also carried out, and the adsorption efficiency of the adsorbents was still up to $67 \%$ after five adsorption-desorption cycles. The hierarchical porous Dt/S-1 composites have an excellent VOC adsorption performance, satisfactory selectivity, and recycling ability.
\end{abstract}

Keywords: Diatomite; silicalite-1; hierarchical porous structure; adsorption; VOCs

\section{Introduction}

Due to fast urbanization and industrialization, the emissions of volatile organic compounds (VOCs) have increased dramatically over the last decade and have received considerable attention because of the severe environmental hazards they create [1]. The term VOCs refers to organic compounds that have a saturated vapor pressure greater than $133.3 \mathrm{~Pa}$ at room temperature and a boiling point that varies from $50{ }^{\circ} \mathrm{C}$ to $260{ }^{\circ} \mathrm{C}$ [2]. VOCs discharged into the atmosphere could become precursors of ozone and secondary organic aerosols by taking part in photochemical reactions with nitrogen oxides under sunlight. The harmful products could furthermore induce photochemical smog and haze and cause serious implications for human health and activities [3].

A number of studies have indicated the effectiveness of VOC removal by adsorption technology. The most frequently used materials for the capture of VOCs are porous substances with large surface areas and pore volume such as zeolites [4], resins [5] and activated carbons together with their derivatives [6-9]. It has been demonstrated that zeolites are desirable materials for the removal of hydrocarbons because of their "tailor-made" physico-chemical properties [10], together with their high thermal and chemical stability and renewable ability [11]. However, most zeolites have a strong hydrophilic function, resulting in water molecules taking up the adsorption sites of organic molecules. 
It has been found that pure silica zeolites tend to be hydrophobic, such as nano-sized silicalite-1 (S-1) of MFI-type zeolite [12]. Nevertheless, two major issues still exist in the application of nano S-1 as adsorbents. On the one hand, the cellular structure of zeolite leads to their adsorption to only a certain size of small organic molecules, which is difficult to meet the actual needs of industries. On the other hand, nanoparticle agglomeration might reduce the effective surface area and lower the adsorption capacity [13-15].

Diatomite (Dt) is a natural siliceous rock composed of microfossils of aquatic algae called diatoms $[16,17]$. Dt is abundant in China with low cost, a unique macroporous structure (50-800 $\mathrm{nm}$ ), and high thermal stability [18]. However, raw Dt exhibits a relatively low adsorption capacity due to its poor surface area. Proper modification would significantly improve the surface properties of raw Dt, considering that raw Dt could be a suitable carrier material [19]. Anderson et al. [20] synthesized a composite by loading S-1 seeds onto Dt. The obtained composite showed a low specific surface area $\left(S_{B E T}, 29.2 \mathrm{~m}^{2} / \mathrm{g}\right)$ and micropore volume $\left(V_{\text {micropore }}, 0.01 \mathrm{~cm}^{3} / \mathrm{g}\right)$. Yuan et al. [21] reported that a hierarchically porous Dt/S-1 composite for benzene adsorption was fabricated via a facile pre-modification in situ synthesis route. The surface area and micropore volume of the composite were improved a lot, however, in situ synthesis without crystal seeds has its limitations such as uneven load and active components easily draining away. Furthermore, as for the application of Dt/S- 1 on VOC adsorption, it is of great significance to explore multi-component and competitive adsorption of VOCs.

In this study, the highly dispersed nano S-1 modified Dt (Dt/S-1) for VOC adsorption was synthesized by a pre-modification and two-step crystallization method. This kind of method could make zeolites grow regularly around S-1 seeds on the surface of Dt, which may avoid zeolites blocking up large pores of $\mathrm{Dt}$ at the same time. The adsorbents were characterized by X-ray diffraction (XRD), scanning electron microscopy (SEM), and Brunauer-Emmett-Teller (BET) analysis. Different preparation conditions such as doping ratio, hydrothermal temperature and hydrothermal time were investigated. Acetone, ethyl acetate, and toluene were used as probe adsorbates to systematically evaluate the adsorption performance of the obtained Dt/S-1 composite. Single-component and multi-component adsorption experiments were exhibited as a comparison. Adsorption kinetics, isotherms and selectivity were included as adsorption assessments. Additionally, the regeneration of the adsorbents was also discussed in this paper.

\section{Materials and Methods}

\subsection{Chemicals}

The synthesis of S-1 zeolite seeds was conducted from a mother solution containing tetraethylorthosilicate, (TEOS, 98\%, Alfa Aesar), tetrapropylammonium hydroxide (TPAOH, $20 \mathrm{wt} \%$ in water, Alfa Aesar) and ultrapure water. Raw Dt powders were obtained from the Changbai deposit in Jilin Province, China. Hydrochloric acid (Beijing Chemical Plant), sodium hydrate ( $\mathrm{NaOH}$, Beijing Chemical Plant), and polydiallyldimethylammonium chloride (PDDA, $20 \mathrm{wt} \%$ in water, Alfa Aesar) were used to modify Dt. Three organic compounds were selected as the probe adsorbates. Acetone $\left(\mathrm{CH}_{3} \mathrm{COCH}_{3}\right)$, ethyl acetate $\left(\mathrm{CH}_{3} \mathrm{COOC}_{2} \mathrm{H}_{5}\right)$, and toluene $\left(\mathrm{CH}_{3} \mathrm{C}_{6} \mathrm{H}_{5}\right)$ were purchased from Beijing Chemical Plant.

\subsection{Preparation of $D t / S-1$ Composites}

\subsubsection{Synthesis of S-1 Zeolite Seeds}

Nano-sized S-1 zeolite was synthesized from a colloidal precursor solution with the following chemical compositions: $25 \mathrm{SiO}_{2}: 9$ TPAOH: $480 \mathrm{H}_{2} \mathrm{O}$. The silica source for the preparation of the initial precursors was TEOS, and the alkali source was TPAOH. These components were mixed under vigorous stirring and aged on an orbital shaker at ambient temperature for $12 \mathrm{~h}$ prior to the further hydrothermal treatment at $100^{\circ} \mathrm{C}$ for 4 days. After the hydrothermal synthesis, the seeds were washed 
3 times by repetitive dispersions in water applying a 5 -min ultrasonic treatment followed by a $10 \mathrm{~min}$ centrifugation at $8000 \mathrm{rpm}$. Finally, the seeds were dried at $60{ }^{\circ} \mathrm{C}$ before being calcined at $550{ }^{\circ} \mathrm{C}$ for 4 $\mathrm{h}$ to remove the organic template.

\subsubsection{Pre-Modification of Dt}

Firstly, Dt was mixed with $6 \mathrm{~mol} / \mathrm{L}$ hydrochloric acid solution to remove impurities [22]. After the mixture was stirred vigorously for $3 \mathrm{~h}$ in a thermostatic bath pot at $60^{\circ} \mathrm{C}$, Dt was washed with deionized water until the $\mathrm{pH}$ reached $7-8$ and dried in a ventilated oven at $60{ }^{\circ} \mathrm{C}$.

Secondly, the Dt treated by acid was further modified with alkali to enlarge the pores to prevent zeolites blocking up the pores. The Dt was mixed with sodium hydroxide solution $(\mathrm{pH}=13.5)$. The mixture was stirred vigorously for $3 \mathrm{~h}$ in a thermostatic bath pot at $60^{\circ} \mathrm{C}$. Then the $\mathrm{Dt}$ was washed until the $\mathrm{pH}$ reached $7-8$ and dried at $60{ }^{\circ} \mathrm{C}$ after separation.

Finally, $1 \mathrm{~g}$ Dt treated as above was mixed with $20 \mathrm{~mL}$ of $0.5 \mathrm{wt} \%$ PDDA solution. PDDA modification could change the surface charge of Dt from negative to positive [23], which was beneficial for combination with negatively charged S-1 seeds resulting from the electrostatic attraction. Then the mixture was stirred for $1 \mathrm{~h}$ and aged for $30 \mathrm{~min}$ before it was washed and dried at $60^{\circ} \mathrm{C}$.

\subsubsection{Seeds-Assisted Synthesis of Dt/S-1 Composites}

A certain amount of nano-sized S-1 zeolite was dispersed into an ammonia solution ( $\mathrm{pH}=9.5)$, then $1 \mathrm{~g}$ modified Dt was added into it. The mixture was stirred for $1 \mathrm{~h}$ and aged for $30 \mathrm{~min}$, then washed 3 times with $0.1 \mathrm{~mol} / \mathrm{L}$ ammonia solution to finish the seeding procedure. Additionally, a certain amount of the seeded sample was mixed with $40 \mathrm{~mL}$ zeolite colloidal precursor solution (reported in Section 2.2.1) for further hydrothermal synthesis at $100^{\circ} \mathrm{C}$ for 4 days. The obtained mixture was washed repeatedly with water, dried at $60^{\circ} \mathrm{C}$, and finally calcined at $550^{\circ} \mathrm{C}$ for $4 \mathrm{~h}$. In this paper, the effect of seeded zeolite content $(1 \mathrm{wt} \%, 5 \mathrm{wt} \%, 10 \mathrm{wt} \%$ and $20 \mathrm{wt} \%)$, hydrothermal temperature $\left(90{ }^{\circ} \mathrm{C}, 100{ }^{\circ} \mathrm{C}\right.$ and $110^{\circ} \mathrm{C}$ ) and hydrothermal time ( 3 days, 4 days and 5 days) were investigated.

\subsection{Characterization of Adsorbents}

X-ray diffraction (XRD) patterns were recorded by an X-ray diffractometer (Bruker D8 ADVANCE, Karlsruhe, German) with a $\mathrm{Cu} K \alpha$ radiation source $(\mathrm{k}=0.154 \mathrm{~nm})$ operated under a generating voltage of $40 \mathrm{kV}$ and a current of $40 \mathrm{~mA}$. Scanning electron microscopy (SEM) images were obtained with a scanning electron microscope (TOPCON ABT-150S, Tokyo, Japan). A Micromeritics ASAP 2020 system was used to measure the $\mathrm{N}_{2}$ adsorption-desorption isotherms $\left(\mathrm{N}_{2}\right.$ adsorption isotherms at $77 \mathrm{~K}$, and all samples were pre-activated at $300{ }^{\circ} \mathrm{C}$ under vacuum for $10 \mathrm{~h}$ ). The surface area was calculated from the $\mathrm{N}_{2}$ adsorption data using the multi-point Brunauer-Emmett-Teller (BET) equation [24]. The micropore volume was obtained via the $\mathrm{t}$-plot method.

\subsection{Adsorption Experiments}

Adsorption experiments were performed in a $125 \mathrm{~mL}$ container with $0.01 \mathrm{~g}$ adsorbents. A specific amount of liquid probe VOC (acetone, ethyl acetate, and toluene) was injected into the container before it was sealed. The liquid organics were converted into vapour and adsorbed by the adsorbents at $60{ }^{\circ} \mathrm{C}$. The concentrations of residual organics were determined by a gas chromatograph device (GC-2014C, SHIMADZU, Japan) equipped with a WonderCap5 column and a flame ionization detector (FID). The temperatures of the inlet, analyzer and column were $240{ }^{\circ} \mathrm{C}, 300{ }^{\circ} \mathrm{C}$ and $70{ }^{\circ} \mathrm{C}$, respectively. The equilibrium time was $4 \mathrm{~min}$. Adsorption experiments were performed with an initial vapour concentration of $0.12 \mathrm{mmol} / \mathrm{L}$, except for adsorption isotherms experiments. Kinetics experiments were performed at different times, ranging from $5 \mathrm{~min}$ to $60 \mathrm{~min}$, while adsorption isotherms experiments were performed with initial vapour concentrations varying from 0.04 $\mathrm{mmol} / \mathrm{L}$ to $0.27 \mathrm{mmol} / \mathrm{L}$. Competitive adsorption experiments were conducted with multi-component vapour in a single container with the same initial concentration. To evaluate regeneration capacity, 
the adsorption-desorption processes of ethyl acetate were performed for 6 cycles, and the desorption experiments were carried out by heating the inactive materials at $120^{\circ} \mathrm{C}$ for $6 \mathrm{~h}$. Equilibrium adsorption capacity, $Q_{e}$, of the adsorbent was calculated as Equation (1):

$$
Q_{e}=\left(C_{0}-C_{e}\right) \cdot V / W
$$

where $C_{0}(\mathrm{mmol} / \mathrm{L})$ and $C_{e}(\mathrm{mmol} / \mathrm{L})$ are the initial and equilibrium concentrations of the adsorbates. $V(\mathrm{~L})$ and $W(\mathrm{~g})$ represent the vapour volume and the mass of $\mathrm{Dt} / \mathrm{S}-1$, respectively.

\section{Results and Discussion}

\subsection{Characterization of the Adsorbents}

\subsubsection{XRD}

The X-ray diffraction (XRD) patterns are shown in Figure 1. The XRD pattern of Dt revealed the main phase of non-crystalline opal-A with the characteristic broad peak centered at $21.8^{\circ}$ [25]. S-1 zeolite samples presented obvious diffraction peaks at about $7.8^{\circ}, 8.8^{\circ}, 14.8^{\circ}, 17.6^{\circ}, 23^{\circ}, 23.6^{\circ}$ and $24.4^{\circ}$, consistent with the crystal characteristic peaks of S-1 in the standard spectra [26]. Compared with S-1, Dt/S-1 (5 wt \%) almost owned the same characteristic diffraction peaks, indicating that S-1 was successfully loaded onto the surface of Dt.

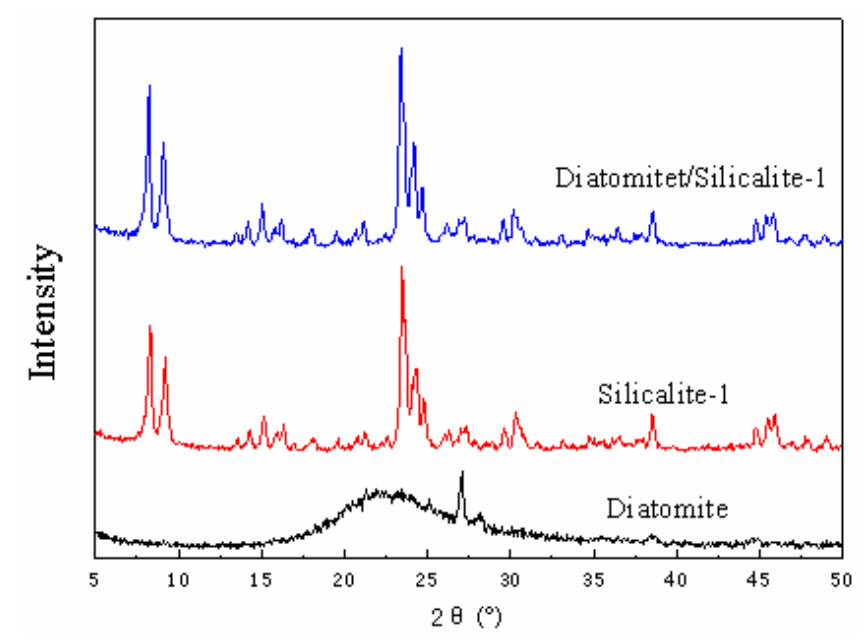

Figure 1. X-ray diffraction (XRD) patterns of diatomite (Dt), silicalite-1 (S-1) and Dt/S-1 (5 wt\%).

\subsubsection{SEM}

SEM observations (Figure 2) revealed the surface appearance of Dt $(a, b)$ and Dt/S-1 (5 wt\%) (c, d). Dt displayed a disk structure with a diameter between $20 \mu \mathrm{m}$ to $25 \mu \mathrm{m}$. In particular, there were large pores around $0.1-0.5 \mu \mathrm{m}$ with a regular distribution. Figure $2 \mathrm{c}, \mathrm{d}$ showed that $\mathrm{Dt}$ was successfully loaded by S-1 crystals with the size of $60-70 \mathrm{~nm}$. Macropores were observed on the composites as shown in Figure 2d. 

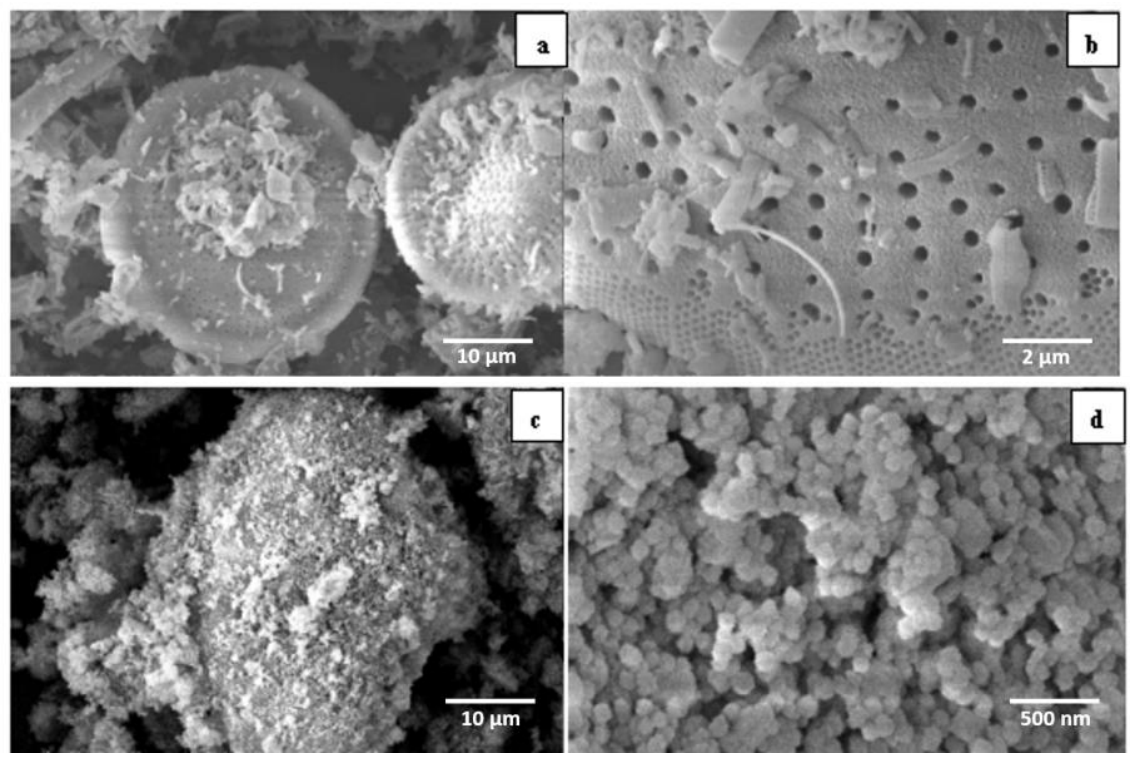

Figure 2. Scanning electron microscopy (SEM) images of Dt (a,b) and Dt/S-1 (5 wt \%) (c,d).

\subsubsection{BET}

The surface properties of Dt, S- 1 and the Dt/S- 1 composites determined by $\mathrm{N}_{2}$ adsorption-desorption were listed in Table 1 and Table S1. The surface area of Dt/S-1 (5 wt\%) was nearly 40 times as large as Dt. The total pore volume and micropore volume of Dt/S-1 (5 wt $\%)$ were both much superior to that of Dt. The considerable porous parameters of the composite were attributed to the nano-sized S-1 coated onto Dt. In addition, the wt $\%$ of zeolite in the composites was calculated using Equation (2) [21]:

$$
W_{\text {zeolite }} \%=\left[V_{\text {micropore }}(\text { composite })-V_{\text {micropore }}(D t)\right] / V_{\text {micropore }}(S-1) \times 100 \%
$$

According to the equation, the $\mathrm{wt} \%$ of zeolite in Dt/S-1 (5 wt\%) was $74.1 \%$, and the content of coated zeolite was higher than the work reported before.

Table 1. Porous parameters of Dt, S-1 and Dt/S-1 (5 wt \%). $S_{B E T}=$ specific surface area. $V_{\text {micropore }}=$ micropore volume. $V_{\text {total }}=$ total volume.

\begin{tabular}{cccc}
\hline Sample & Dt & S-1 & Dt/S-1 (5 wt\%) \\
\hline$S_{B E T}\left(\mathrm{~m}^{2} / \mathrm{g}\right)$ & 10.0 & 532.0 & 398.8 \\
$V_{\text {micropore }}\left(\mathrm{cm}^{3} / \mathrm{g}\right)$ & 0.005 & 0.170 & 0.131 \\
$V_{\text {total }}\left(\mathrm{cm}^{3} / \mathrm{g}\right)$ & 0.045 & 0.515 & 0.342 \\
\hline
\end{tabular}

Figure 3 showed the $\mathrm{N}_{2}$ adsorption-desorption isotherms of Dt, S-1 and Dt/S-1 (5 wt\%). The isotherm of raw Dt featured a type II curve with a minor H3 hysteresis loop according to the IUPAC classification [27], which indicated that Dt contained small quantities of mesopores. When $\mathrm{P} / \mathrm{P}_{0} \leq 0.1$, Dt had poor adsorption to $\mathrm{N}_{2}$, which implies that Dt had few micropores. The rapidly increased adsorption quantities when $\mathrm{P} / \mathrm{P}_{0} \approx 1.0$ suggest abundant macroporosity. S- 1 had a type IV adsorption-desorption isotherm curve with an evident $\mathrm{H} 3$ hysteresis loop, which was an indication of the formation of mesopores from the nano-crystal stacking. The adsorption of $\mathrm{N}_{2}$ on S-1 increased rapidly while $\mathrm{P} / \mathrm{P}_{0} \leq 0.1$ because of the rapid filling of $\mathrm{N}_{2}$ into the micropores of zeolites. In addition, the adsorption rose again rapidly when $\mathrm{P} / \mathrm{P}_{0} \approx 1.0$ according to the nano-size effect and particle agglomeration. The Dt/S-1 (5 wt \%) had a type IV adsorption-desorption isotherm curve and evident $\mathrm{H} 3$ hysteresis loop, and the adsorption of $\mathrm{N}_{2}$ increased rapidly while $\mathrm{P} / \mathrm{P}_{0} \leq 0.1$, similar to $\mathrm{S}-1$, indicating that the composite consisted of nano-sized S-1 particles. Finally, the increasing trend of 
$\mathrm{N}_{2}$ adsorption of $\mathrm{Dt} / \mathrm{S}-1(5 \mathrm{wt} \%)$ in the high pressure region $\left(\mathrm{P} / \mathrm{P}_{0} \approx 1.0\right)$ was moderated compared with that of S-1, which explained that the composite materials still had a considerable number of large pores. Above all, the hierarchical porous structure was synthesized successfully, making up for the disadvantages of pure $\mathrm{Dt}$ and zeolite. The other samples had similar $\mathrm{N}_{2}$ adsorption-desorption isotherms to Dt/S-1 (5 wt\%) which are shown in Figure S1.

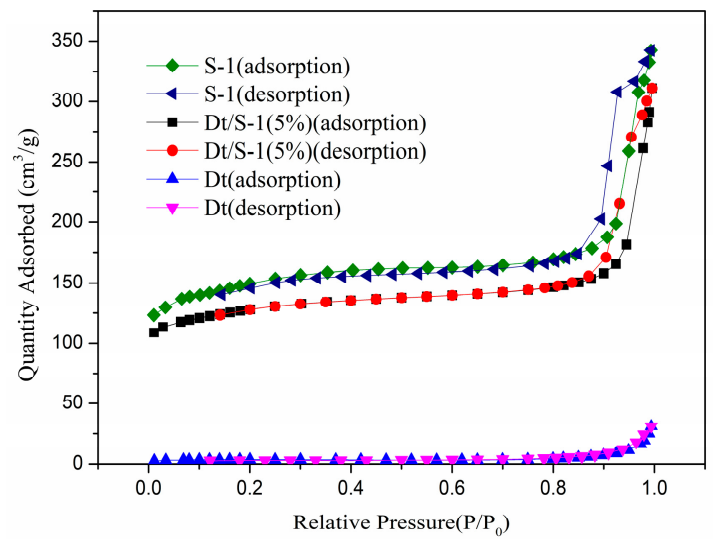

Figure 3. $\mathrm{N}_{2}$ adsorption-desorption isotherms of Dt, S-1 and Dt/S-1 (5 wt\%).

\subsection{VOC Adsorption Capacity Tests}

\subsubsection{Effects of Seeded Zeolite Contents and Hydrothermal Conditions}

The equilibrium adsorption capacities for the adsorption of three VOCs on various adsorbents were exhibited in Table 2. Experimental results showed that the adsorption capacities of the adsorbents with different loadings of S-1 seeds were 4-22 times that of Dt. In addition, with the increase of seed content from $1 \mathrm{wt} \%$ to $10 \mathrm{wt} \%$, ethyl acetate adsorption capacities on the adsorbents were improved from $1.10 \mathrm{mmol} / \mathrm{g}$ to $1.31 \mathrm{mmol} / \mathrm{g}$, and the specific surface area of the samples increased from $319.2 \mathrm{~m}^{2} / \mathrm{g}$ to $402.3 \mathrm{~m}^{2} / \mathrm{g}$ (Table S1). However, the adsorption capacities of the three VOCs declined obviously as the seed content increased up to $20 \mathrm{wt} \%$. The specific surface area of Dt/S-1 (20 $\mathrm{wt} \%$ ) decreased to $336.8 \mathrm{~m}^{2} / \mathrm{g}$. While the micropore volume improved, the total volume had decreased, indicating that the dispersed S-1 nanocrystals were occupied inside the pores of Dt. On the one hand, the hierarchical porous structure of Dt/S-1 enhanced the efficiency of large Dt pores and made up for the shortcomings of pure zeolite for its limited pore size distribution. On the other hand, the dispersion of S-1 on Dt could reduce the agglomeration of nanoparticles and decrease mass transfer resistance. S-1 seeds played a guiding role in the growth of zeolite, but excessive load might cause overgrowth of crystals and lead to particle agglomeration, reducing the surface area of the adsorbents exposed to probe VOCs. The adsorption effect of Dt/S-1 (5 wt\%) and Dt/S-1 (10 wt $\%)$ were similar to pure S-1. Considering the actual content of zeolite in the composites (74.1\% in Dt/S-1 $(5 \mathrm{wt} \%))$, the utilization efficiency of zeolite was greatly improved. Moreover, due to the introduction of diatomite, the synthesis cost of the composite material is significantly lower than that of pure S-1 zeolite.

Table 2. Equilibrium adsorption capacities $(\mathrm{mmol} / \mathrm{g})$ of three probe volatile organic compounds (VOCs) on various adsorbents.

\begin{tabular}{|c|c|c|c|c|c|c|}
\hline \multicolumn{5}{|c|}{ Dt/S-1 (wt\%) } & \multirow{2}{*}{ S-1 } & \multirow{2}{*}{$\mathrm{Dt}$} \\
\hline Sample & 1 & 5 & 10 & 20 & & \\
\hline Acetone & $0.82 \pm 0.04$ & $1.01 \pm 0.06$ & $1.02 \pm 0.05$ & $0.80 \pm 0.04$ & $1.01 \pm 0.05$ & $0.07 \pm 0.002$ \\
\hline Ethyl acetate & $1.10 \pm 0.05$ & $1.31 \pm 0.08$ & $1.28 \pm 0.08$ & $0.92 \pm 0.04$ & $1.28 \pm 0.08$ & $0.06 \pm 0.002$ \\
\hline Toluene & $0.62 \pm 0.02$ & $0.71 \pm 0.03$ & $0.69 \pm 0.02$ & $0.48 \pm 0.01$ & $0.72 \pm 0.03$ & $0.12 \pm 0.005$ \\
\hline
\end{tabular}


The adsorption capacities of probe VOCs were ethyl acetate $>$ acetone $>$ toluene. According to existing research, the interaction between adsorbents and adsorbates is mostly the consequence of the comprehensive effect of adsorbents' pore canal structure and adsorbates' physicochemical qualities [28-33]. S-1 zeolite possessed sinusoidal channels with $0.54 \mathrm{~nm}$ circular cross-sections interconnected with straight channels with $0.51 \mathrm{~nm} \times 0.57 \mathrm{~nm}$ elliptical cross sections [34]. If the adsorption became effective and stable, the adsorbent's pore size must be close to the size of the adsorbates [30]. The sizes of acetone and ethyl acetate were in the effective range of adsorption, but toluene was not. Abundant research has indicated that high-silica MFI-type zeolites have a nonpolar nature [12], and thus S-1 zeolite tended to adsorb substances of low polarity. Since the polarity of ethyl acetate was smaller than acetone, according to the like-dissolves-like theory, the composite adsorbents were more likely to adsorb ethyl acetate rather than acetone.

The equilibrium adsorption capacities of Dt/S-1 (5 wt \%) prepared at different hydrothermal temperatures are shown in Table 3. The adsorbent synthesized at $100^{\circ} \mathrm{C}$ showed the most considerable adsorption capacity, which was superior to the adsorbents synthesized at $90^{\circ} \mathrm{C}$ and $110^{\circ} \mathrm{C}$. With the increase in temperature, the crystallinity was improved accordingly (Figure S2). Nevertheless, higher temperatures would cause the growth of over-sized molecules or the agglomeration of particles, and then had a negative impact on the surface area and pore volume of the adsorbents [35].

Table 3. Equilibrium adsorption capacities (mmol/g) of Dt/S-1 (5 wt \%) prepared at different temperatures.

\begin{tabular}{cccc}
\hline Sample & $\mathbf{9 0}{ }^{\circ} \mathbf{C}$ & $\mathbf{1 0 0}{ }^{\circ} \mathbf{C}$ & $\mathbf{1 1 0}{ }^{\circ} \mathbf{C}$ \\
\hline Acetone & $0.58 \pm 0.02$ & $1.01 \pm 0.06$ & $0.97 \pm 0.05$ \\
Ethyl acetate & $0.90 \pm 0.05$ & $1.31 \pm 0.08$ & $1.22 \pm 0.07$ \\
Toluene & $0.48 \pm 0.02$ & $0.71 \pm 0.04$ & $0.68 \pm 0.03$ \\
\hline
\end{tabular}

Table 4 shows the equilibrium adsorption capacities of Dt/S-1 (5 wt\%) prepared at different hydrothermal times. The results showed that the adsorbent synthesized for four days had the most desirable adsorption capacity. With the increase in hydrothermal time, the overgrowth of S-1 zeolite might lead to the occlusion of Dt's large pores [36] and reduce the adsorption efficiency of the adsorbents.

Table 4. Equilibrium adsorption capacities $(\mathrm{mmol} / \mathrm{g})$ of Dt/S-1 $(5 \mathrm{wt} \%)$ prepared at different times.

\begin{tabular}{cccc}
\hline Sample & 3 Days & 4 Days & 5 Days \\
\hline Acetone & $0.88 \pm 0.05$ & $1.01 \pm 0.06$ & $0.98 \pm 0.05$ \\
Ethyl acetate & $1.17 \pm 0.06$ & $1.31 \pm 0.08$ & $1.19 \pm 0.07$ \\
Toluene & $0.71 \pm 0.04$ & $0.71 \pm 0.03$ & $0.69 \pm 0.04$ \\
\hline
\end{tabular}

\subsubsection{Adsorption Kinetics}

Figure 4 demonstrates the kinetic adsorption process of Dt/S-1 ( $5 \mathrm{wt} \%)$ to probe VOCs. It took 25 $\mathrm{min}, 35 \mathrm{~min}$ and $45 \mathrm{~min}$ for toluene, acetone and ethyl acetate to reach the adsorption equilibrium, respectively. Experimentally determined kinetic data were analyzed using nonlinear pseudo first-order and pseudo second-order models using Equations (3) and (4) [37]:

$$
\begin{gathered}
Q_{t}=Q_{e}\left(1-e^{-k_{1} t}\right) \\
Q_{t}=\frac{k_{2} Q_{e}^{2} t}{1+k_{2} Q_{e} t}
\end{gathered}
$$

where, $k_{1}\left(\mathrm{~min}^{-1}\right)$ is the pseudo first-order rate constant of adsorption, $k_{2}\left(\mathrm{~g} \cdot \mathrm{mol}^{-1} \mathrm{~min}^{-1}\right)$ is the pseudo second-order rate constant of adsorption, $Q_{e}\left(\mathrm{~mol} \cdot \mathrm{g}^{-1}\right)$ is the adsorption capacity at equilibrium and $Q_{t}\left(\mathrm{~mol} \cdot \mathrm{g}^{-1}\right)$ is the adsorption capacity at a given time $t$. 


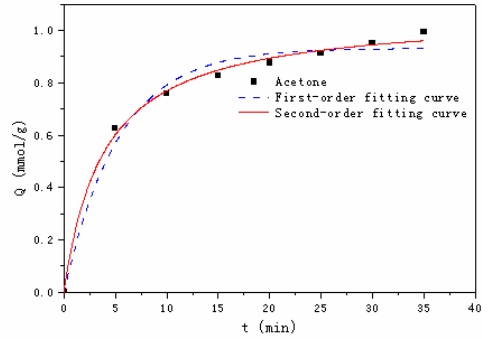

(a)

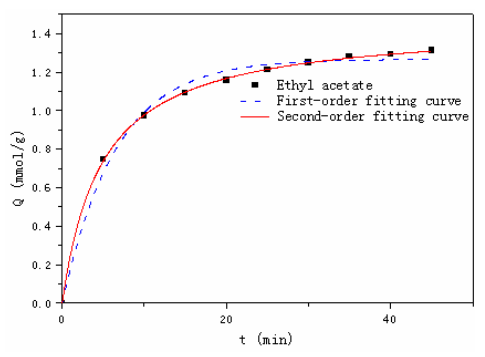

(b)

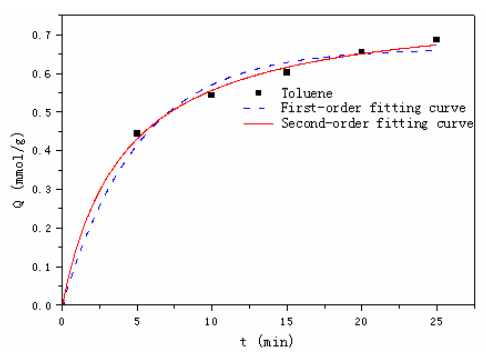

(c)

Figure 4. Kinetic adsorption process of Dt/S-1 (5 wt\%) to acetate (a), ethyl acetate (b) and toluene (c).

The obtained kinetic parameters were shown in Table 5. It was noted that $Q_{e}(\exp )$ represents data from experiments, while $Q_{e}$ (cal) represents data from model fittings. It was observed that the pseudo second-order model well fit the experimental data of the three organic compounds with a higher correlation coefficient $\left(R^{2}\right)$. Also, $Q_{e}(\mathrm{cal})$ values from the pseudo second-order model were found to agree better to the experimentally obtained $Q_{e}(\exp )$. The fitting results thus indicated that the adsorption rate was mainly determined by the chemical adsorption process [37].

Table 5. Adsorption kinetics parameters of three probe VOCs. $Q_{e}=$ adsorption capacity at equilibrium. $k_{1}=$ pseudo first-order rate constant of adsorption. $k_{2}=$ pseudo second-order rate constant of adsorption. $R^{2}=$ correlation coefficient.

\begin{tabular}{cccccccc}
\hline Model & \multicolumn{3}{c}{ Pseudo First-Order Model } & \multicolumn{3}{c}{ Pseudo Second-Order Model } \\
\hline Parameter & $Q_{e}(\mathrm{exp}, \mathrm{mmol} / \mathrm{g})$ & $Q_{e}(\mathrm{cal}, \mathrm{mmol} / \mathrm{g})$ & $k_{1}$ & $R^{2}$ & $Q_{e}(\mathrm{cal}, \mathrm{mmol} / \mathrm{g})$ & $k_{2}$ & $R^{2}$ \\
Acetone & 0.99 & 0.91 & 0.21 & 0.9874 & 1.04 & 0.27 & 0.9981 \\
Ethyl acetate & 1.31 & 1.22 & 0.17 & 0.9908 & 1.39 & 0.17 \\
Toluene & 0.69 & 0.62 & 0.22 & 0.9948 & 0.75 & 0.35 & 0.9995 \\
\hline
\end{tabular}

\subsubsection{Adsorption Isotherms}

Figure 5 demonstrated that the adsorbed amount of probe VOCs on Dt/S-1 (5 wt $\%$ ) increased with increasing initial concentrations. In order to figure out adsorption isotherms of the adsorbent, the Henry model, Langmuir model and Freundlich model were utilized with Equations (5)-(7) [38]:

$$
\begin{gathered}
Q_{e}=k_{H} C_{e} \\
Q_{e}=\frac{Q_{\max } k_{L} C_{e}}{1+k_{L} C_{e}} \\
Q_{e}=k_{F} C_{e}^{1 / n}
\end{gathered}
$$

where $Q_{\max }\left(\mathrm{mol} \cdot \mathrm{g}^{-1}\right)$ is the maximum adsorption capacity, $k_{H}$ is the Henry constant $\left(\mathrm{L} \cdot \mathrm{g}^{-1}\right), k_{L}$ $\left(\mathrm{L} \cdot \mathrm{mmol}^{-1}\right)$ is the Langmuir equilibrium constant, $k_{F}\left(\mathrm{mmol}^{1-\mathrm{n}} \cdot \mathrm{L}^{\mathrm{n}} \cdot \mathrm{g}^{-1}\right)$ is the Freundlich constant and $1 / \mathrm{n}$ is the heterogeneity factor.

The adsorption isotherm parameters are listed in Table 6. The Langmuir model yields a much better fit than that of the Henry model or the Freundlich model, indicating that the adsorption process happened on a monolayer. 


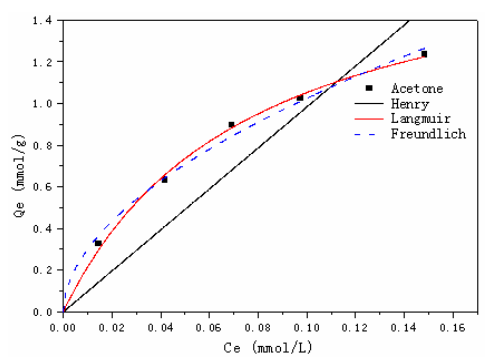

(a)

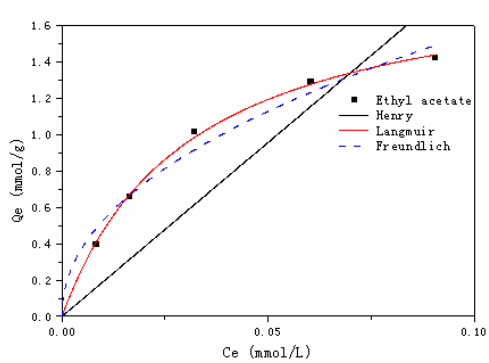

(b)

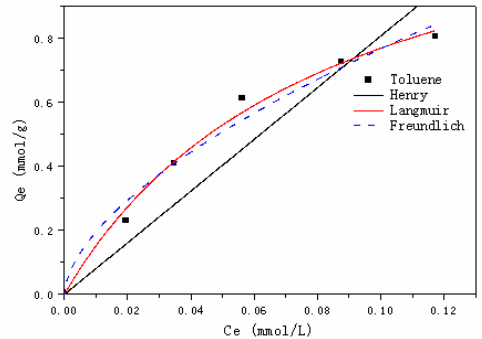

(c)

Figure 5. Equilibrium adsorption capacities of acetate (a), ethyl acetate (b) and toluene (c) at different equilibrium concentrations.

Table 6. Adsorption isotherm parameters of three probe VOCs. $Q_{\max }\left(\mathrm{mol} \cdot \mathrm{g}^{-1}\right)=$ maximum adsorption capacity. $k_{H}\left(\mathrm{~L} \cdot \mathrm{g}^{-1}\right)=$ Henry constant. $k_{\mathrm{L}}\left(\mathrm{L} \cdot \mathrm{mmol}^{-1}\right)=$ Langmuir equilibrium constant. $k_{F}$ $\left(\mathrm{mmol}^{1-\mathrm{n}} \cdot \mathrm{L}^{\mathrm{n}} \cdot \mathrm{g}^{-1}\right)=$ Freundlich constant. $1 / \mathrm{n}=$ heterogeneity factor.

\begin{tabular}{ccccccccc}
\hline Model & \multicolumn{2}{c}{ Henry } & \multicolumn{3}{c}{ Langmuir } & \multicolumn{3}{c}{ Freundhch } \\
\hline Parameter & $k_{H}$ & $R^{2}$ & $k_{L}$ & $Q_{\max }$ & $R^{2}$ & $k_{F}$ & $n$ & $R^{2}$ \\
Acetone & 9.84 & 0.8250 & 13.24 & 1.85 & 0.9974 & 3.50 & 0.53 & 0.9933 \\
Ethyl & 19.15 & 0.7028 & 32.45 & 1.93 & 0.9986 & 4.62 & 0.47 & 0.9787 \\
acetate & 8.08 & 0.8601 & 12.07 & 1.41 & 0.9903 & 3.03 & 0.60 & 0.9743 \\
Toluene & & & & & & & &
\end{tabular}

\subsubsection{Adsorption Selectivity}

In addition to single-component adsorption, this study also explored multi-component adsorption onto Dt/S-1 (5 wt\%). Figure 6 presents the competitive adsorption of three probe VOCs with the same initial vapor concentrations. After five minutes, the adsorption value of acetone was close to ethyl acetate, and the adsorption of toluene was far lower than the former two organics. Subsequently, the adsorption of ethyl acetate continued to increase, while the adsorption of acetone decreased sharply. After $45 \mathrm{~min}$, adsorption of the three VOCs reached an equilibrium. In comparison with the adsorption of a single component, the adsorption capacities decreased since adsorption competition existed among the three probe organics. In a comprehensive way, single-component and multi-component adsorption experiments showed that the composite had the capability of selective adsorption to ethyl acetate.

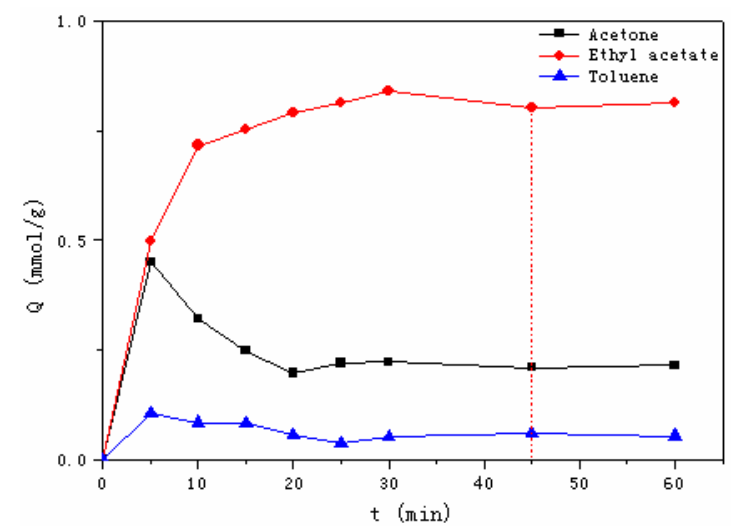

Figure 6. Competitive adsorption of acetate, ethyl acetate and toluene. 
The distribution coefficient $\left(K_{d}\right)$ was used to analyze the selectivity of the absorbent toward three probe VOCs. The equation is stated as [39]:

$$
k_{d}=\frac{V \cdot\left(C_{0}-C_{e}\right)}{m \cdot C_{e}}
$$

where $C_{0}$ and $C_{e}(\mathrm{mmol} / \mathrm{L})$ represent the initial and equilibrium concentrations of solutes, respectively; $V(\mathrm{~L})$ is the volume of solution; and $m(\mathrm{~g})$ is the mass of the adsorbent.

A selectivity coefficient $(\alpha)$ for the binding of a particular adsorbate in the presence of interfering compounds is defined in Equation (9) as [39]:

$$
\alpha=k_{d}(T) / k_{d}(I)
$$

where $K_{d}(\mathrm{~T})$ is the $K_{d}$ value of the targeted compound (ethyl acetate in this case) and $K_{d}(\mathrm{I})$ is the $K_{d}$ value of the other compound in the multi-substance mixtures (acetone or toluene here). A larger value of $\alpha$ indicates greater selectivity toward ethyl acetate than acetone or toluene. The calculated $k_{d}$ of acetone, ethyl acetate and toluene were $6.25,15$ and $0.47 \mathrm{~L} / \mathrm{g}$, and the $\alpha$ values of ethyl acetate to acetone and toluene were 2.4 and 31.91, respectively. These results showed better adsorption capacities for ethyl acetate than acetone or toluene, indicating that Dt/S-1 (5wt\%) had selective adsorption toward ethyl acetate.

\subsubsection{Regeneration of the Adsorbents}

The regeneration of Dt/S-1 (5 $\mathrm{wt} \%)$ was carried out by performing five consecutive adsorption-desorption cycles under the same experimental conditions. Figure 7 illustrates the adsorption capacities of Dt/S-1 (5 wt\%) at different adsorption-desorption cycles. The adsorption capacities decreased from the first to the fifth cycle from $85.4 \%$ to $67 \%$, which could be attributed to the remaining VOCs in the adsorbents during the regeneration process or the morphology change of Dt/S-1 (5 wt\%) [40]. After five cycles, the adsorption efficiency was still more than $60 \%$. Therefore, we could conclude that Dt/S-1 (5 wt\%) was suitable for its use and reuse with high removal and recovery. Regeneration is the premise of adsorbents recycling. It is of great significance to reduce the operating cost and increase the spread of adsorption technology.

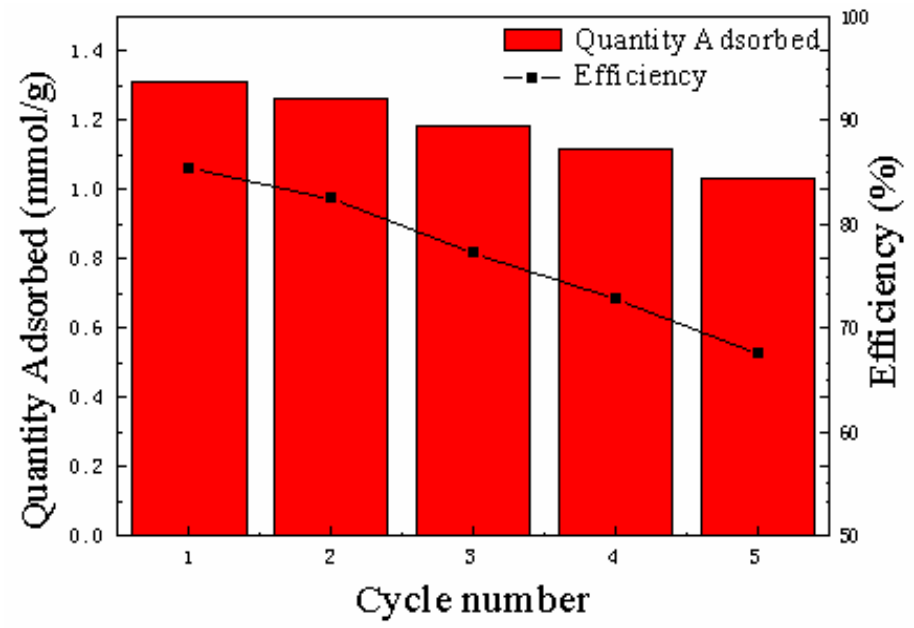

Figure 7. Ethyl acetate adsorption capacities ( $\mathrm{mmol} / \mathrm{g}$ ) and efficiency (\%) for the use of Dt/S-1 (5 wt $\%$ ) at different adsorption-desorption cycles (up to five).

\section{Conclusions}

In this paper, nano S-1 seeds were loaded onto the surface of Dt using the advanced hydrothermal method, which was characterized by XRD, SEM and BET. The Dt/S-1 (5 wt $\%)$ exhibited a considerably 
higher VOC adsorption capacity compared to raw Dt and other composites prepared under different conditions. The pseudo second-order model provided the perfect fit to the dynamic behavior of VOC adsorption onto the composite material for the whole contact time period, while the Langmuir model agreed the best with the adsorption isotherms in terms of different initial concentrations. Further study discovered that the composite had selective adsorption to ethyl acetate among the three VOCs. With a considerable regeneration capacity, the composite material rendered its potential for application in VOC removal techniques.

Supplementary Materials: The following are available online at http:/ /www.mdpi.com/1996-1944/12/4/551/s1, Figure S1: N2 adsorption-desorption isotherms of Dt/S-1(1 wt \%), Dt/S-1(10 wt \%) and Dt/S-1(20 wt $\%)$, Figure S2: X-ray diffraction (XRD) patterns of the Dt/S-1(5 wt \%) synthesized at different temperature, Table S1: Porous parameters of Dt, S-1 and Dt/S-1(5 wt\%).

Author Contributions: Validation, Y.L.; Formal Analysis, Y.L.; Investigation, Y.L.; Resources, T.T.; Writing-Original Draft Preparation, Y.L.; Writing-Review \& Editing, T.T.

Funding: This work was funded by National Natural Science Foundation of China (21771080), Science and Technology Project of the "13th Five-Year Plan" of Jilin Provincial Department of Education (JJKH20180166KJ).

Acknowledgments: We are thankful for support of this work by the State Key Laboratory of Inorganic Synthesis \& Preparative Chemistry, Jilin University.

Conflicts of Interest: The authors declare no conflict of interest.

\section{References}

1. Kim, K.J.; Ahn, H.G. The effect of pore structure of zeolite on the adsorption of VOCs and their desorption properties by microwave heating. Microporous Mesoporous Mater. 2012, 152, 78-83. [CrossRef]

2. Brown, S.K.; Sim, M.R.; Abramson, M.J.; Gray, C.N. Concentrations of Volatile Organic Compounds in Indoor Air-A Review. Indoor Air 1994, 4, 123-134. [CrossRef]

3. Choudhary, V.R.; Mantri, K. Adsorption of aromatic hydrocarbons on highly siliceous MCM-41. Langmuir 2000, 16, 7031-7037. [CrossRef]

4. Pires, J.; Carvalho, A.; de Carvalho, M.B. Adsorption of volatile organic compounds in Y zeolites and pillared clays. Microporous Mesoporous Mater. 2001, 43, 277-287. [CrossRef]

5. Cheng, H.F.; Reinhard, M. Sorption of trichloroethylene in hydrophobic micropores of dealuminated $\mathrm{Y}$ zeolites and natural minerals. Environ. Sci. Technol. 2006, 40, 7694-7701. [CrossRef] [PubMed]

6. Liu, P.; Long, C.; Li, Q.; Qian, H.; Li, A.; Zhang, Q. Adsorption of trichloroethylene and benzene vapors onto hypercrosslinked polymeric resin. J. Hazard. Mater. 2009, 166, 46-51. [CrossRef] [PubMed]

7. Das, D.; Gaur, V.; Verma, N. Removal of volatile organic compound by activated carbon fiber. Carbon 2004, 42, 2949-2962. [CrossRef]

8. Lordgooei, M.; Rood, M.J.; Rostam-Abadi, M. Modeling effective diffusivity of volatile organic compounds in activated carbon fiber. Environ. Sci. Technol. 2001, 35, 613-619. [CrossRef]

9. Aizpuru, A.; Malhautier, L.; Roux, J.C.; Fanlo, J.L. Biofiltration of a mixture of volatile organic compounds on granular activated carbon. Biotechnol. Bioeng. 2003, 83, 479-488. [CrossRef]

10. Cundy, C.S.; Cox, P.A. The hydrothermal synthesis of zeolites: history and development from the earliest days to the present time. Chem. Rev. 2003, 103, 663-702. [CrossRef]

11. Giannakopoulos, I.G.; Nikolakis, V. Recovery of hydrocarbons from mixtures containing $\mathrm{C}_{3} \mathrm{H}_{6}, \mathrm{C}_{3} \mathrm{H}_{8}$ and N2 using NaX membranes. J. Membr. Sci. 2007, 305, 332-337. [CrossRef]

12. Farzaneh, A.; DeJaco, R.F.; Ohlin, L.; Holmgren, A.; Siepmann, J.I.; Grahn, M. Comparative Study of the Effect of Defects on Selective Adsorption of Butanol from Butanol/Water Binary Vapor Mixtures in Silicalite-1 Films. Langmuir 2017, 33, 8420-8427. [CrossRef] [PubMed]

13. Li, W.C.; Lu, A.H.; Palkovits, R.; Schmidt, W.; Spliethoff, B.; Schuth, F. Hierarchically structured monolithic silicalite-1 consisting of crystallized nanoparticles and its performance in the Beckmann rearrangement of cyclohexanone oxime. J. Am. Chem. Soc. 2005, 127, 12595-12600. [CrossRef] [PubMed]

14. Burggraaf, A.J.; Vroon, Z.A.E.P.; Keizer, K.; Verweij, H. Permeation of single gases in thin zeolite MFI membranes. J. Membr. Sci. 1998, 144, 77-86. [CrossRef] 
15. Gu, X.; Dong, J.; Nenoff, T.M.; Ozokwelu, D.E. Separation of p-xylene from multicomponent vapor mixtures using tubular MFI zeolite mmbranes. J. Membrane Sci. 2006, 280, 624-633. [CrossRef]

16. Erdem, E.; Colgecen, G.; Donat, R. The removal of textile dyes by diatomite earth. J. Colloid Interface Sci. 2005, 282, 314-319. [CrossRef]

17. Al-Degs, Y.; Khraisheh, M.A.M.; Tutunji, M.F. Sorption of lead ions on diatomite and manganese oxides modified diatomite. Water Res. 2001, 35, 3724-3728. [CrossRef]

18. Xie, F.; Wu, F.; Liu, G.; Mu, Y.; Feng, C.; Wang, H.; Giesy, J.P. Removal of phosphate from eutrophic lakes through adsorption by in situ formation of magnesium hydroxide from diatomite. Environ. Sci. Technol. 2014, 48, 582-590. [CrossRef]

19. Khraisheh, M.; Aldegs, Y.; McMinn, W. Remediation of wastewater containing heavy metals using raw and modified diatomite. Angew. Chem. Int. Ed. 2004, 99, 177-184. [CrossRef]

20. Aderson, M.W.; Holms, S.M.; Hanif, N.; Cundy, C.S. Hierarchical pore structures through Diatom Zeolitization. Angew. Chem. Int. Ed. 2000, 39, 2707-2709. [CrossRef]

21. Yuan, W.; Yuan, P.; Liu, D.; Deng, L.; Zhou, J.; Yu, W.; Chen, F. A hierarchically porous diatomite/silicalite-1 composite for benzene adsorption/desorption fabricated via a facile pre-modification in situ synthesis route. Chem. Eng. J. 2016, 294, 333-342. [CrossRef]

22. Yuan, P.; Yang, D.; Lin, Z.; He, H.; Wen, X.; Wang, L.; Deng, F. Influences of pretreatment temperature on the surface silylation of diatomaceous amorphous silica with trimethylchlorosilane. J. Non-Cryst. Solids 2006, 352, 3762-3771. [CrossRef]

23. Panacek, A.; Balzerova, A.; Prucek, R.; Ranc, V.; Vecerova, R.; Husickova, V.; Pechoušek, J.; Filip, J.; Zbořil, R.; Kvítek, L. Preparation, characterization and antimicrobial efficiency of Ag/PDDA-diatomite nanocomposite. Colloids Surf. B 2013, 110, 191-198. [CrossRef] [PubMed]

24. Brunauer, S.; Emmett, P.H.; Teller, E. Adsorption of gases in multimolecular layers. J. Am. Chem. Soc. 1938, 60, 309-319. [CrossRef]

25. Yuan, P.; Liu, D.; Tan, D.Y.; Liu, K.K.; Yu, H.G.; Zhong, Y.H.; Yuan, A.H.; Yu, W.B.; He, H.P. Surface silylation of mesoporous/macroporous diatomite (diatomaceous earth) and its function in $\mathrm{Cu}(\mathrm{II})$ adsorption: The effects of heating pretreatment. Microporous Mesoporous Mater. 2013, 170, 9-19. [CrossRef]

26. Holland, B.T.; Abrams, L.; Stein, A. Dual templating of macroporous silicates with zeolitic microporous frameworks. J. Am. Chem. Soc. 1999, 121, 4308-4309. [CrossRef]

27. Yuan, P.; Liu, D.; Fan, M.; Yang, D.; Zhu, R.; Ge, F.; Zhu, J.; He, H. Removal of hexavalent chromium [Cr(VI)] from aqueous solutions by the diatomite-supported/unsupported magnetite nanoparticles. J. Hazard. Mater. 2010, 173, 614-621. [CrossRef] [PubMed]

28. Zhang, X.; Gao, B.; Creamer, A.E.; Cao, C.; Li, Y. Adsorption of VOCs onto engineered carbon materials: A review. J. Hazard. Mater. 2017, 338, 102-123. [CrossRef]

29. Li, L.; Liu, S.; Liu, J. Surface modification of coconut shell based activated carbon for the improvement of hydrophobic VOC removal. J. Hazard. Mater. 2011, 192, 683-690. [CrossRef]

30. Jhung, S.H.; Yoon, J.W.; Lee, J.S.; Chang, J.S. Low-temperature adsorption/storage of hydrogen on FAU, $\mathrm{MFI}$, and MOR zeolites with various $\mathrm{Si} / \mathrm{Al}$ ratios: effect of electrostatic fields and pore structures. Chemistry 2007, 13, 6502-6507. [CrossRef]

31. Jahandar, L.M.; Atkinson, J.D.; Hashisho, Z.; Phillips, J.H.; Anderson, J.E.; Nichols, M. The role of beaded activated carbon's surface oxygen groups on irreversible adsorption of organic vapors. J. Hazard. Mater. 2016, 317, 284-294. [CrossRef] [PubMed]

32. Qian, Q.; Gong, C.; Zhang, Z.; Yuan, G. Removal of VOCs by activated carbon microspheres derived from polymer: a comparative study. Adsorption 2015, 21, 333-341. [CrossRef]

33. Fletcher, A.J.; Yüzak, Y.; Thomas, K.M. Adsorption and desorption kinetics for hydrophilic and hydrophobic vapors on activated carbon. Carbon 2006, 44, 989-1004. [CrossRef]

34. Xomeritakis, G.; Tsapatsis, M. Permeation of aromatic isomer vapors through oriented MFI-type membranes made by secondary growth. Chem. Mater. 1999, 11, 875-878. [CrossRef]

35. Ali, S.; Wang, F.; Zubair Iqbal, M.; Ullah Shah, H.; Zafar, S. Hydrothermal synthesis, characterization and optical properties of SnS prismatic nanorods. Mater. Lett. 2017, 206, 22-25. [CrossRef]

36. Song, W.; Justice, R.E.; Jones, C.A.; Grassian, V.H.; Larsen, S.C. Size-dependent properties of nanocrystalline silicalite synthesized with systematically varied crystal sizes. Langmuir 2004, 20, 4696-4702. [CrossRef] [PubMed] 
37. Zhao, S.; Huang, G.; Mu, S.; An, C.; Chen, X. Immobilization of phenanthrene onto gemini surfactant modified sepiolite at solid/aqueous interface: Equilibrium, thermodynamic and kinetic studies. Sci. Total Environ. 2017, 598, 619-627. [CrossRef] [PubMed]

38. Ashour, R.M.; El-sayed, R.; Abdel-Magied, A.F.; Abdel-khalek, A.A.; Ali, M.M.; Forsberg, K.; Uheidaa, A.; Muhammedf, M.; Duttaa, J. Selective separation of rare earth ions from aqueous solution using functionalized magnetite nanoparticles: kinetic and thermodynamic studies. Chem. Eng. J. 2017, 327, 286-296. [CrossRef]

39. Deng, J.; Liu, Y.; Liu, S.; Zeng, G.; Tan, X.; Huang, B.; Tang, X.; Wang, S.; Hua, Q.; Yan, Z. Competitive adsorption of $\mathrm{Pb}(\mathrm{II}), \mathrm{Cd}(\mathrm{II})$ and $\mathrm{Cu}(\mathrm{II})$ onto chitosan-pyromellitic dianhydride modified biochar. J Colloid Interface Sci. 2017, 506, 355-364. [CrossRef]

40. Abo Markeb, A.; Alonso, A.; Sanchez, A.; Font, X. Adsorption process of fluoride from drinking water with magnetic core-shell Ce-Ti@ $\mathrm{Fe}_{3} \mathrm{O}_{4}$ and Ce-Ti oxide nanoparticles. Sci. Total Environ. 2017, 598, 949-958. [CrossRef]

(C) 2019 by the authors. Licensee MDPI, Basel, Switzerland. This article is an open access article distributed under the terms and conditions of the Creative Commons Attribution (CC BY) license (http://creativecommons.org/licenses/by/4.0/). 